C2020. Licensed under the Creative Commons Attribution-NonCommercial-NoDerivatives 4.0 International http://creativecommons.org/about/downloads

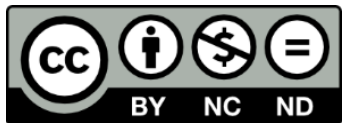

Full published version available at https://doi.org/10.1016/j.erss.2020.101898 
Alternative energy imaginaries: implications for energy research, policy integration and the transformation of energy systems

Audley Genus ${ }^{\text {a }}$, Marfuga Iskandarova ${ }^{2}$, Gary Goggins ${ }^{3}$, Frances Fahy ${ }^{3}$, Senja Laakso ${ }^{4}$

\section{${ }^{a}$ Corresponding author}

${ }^{1}$ Small Business Research Centre, Kingston University London, United Kingdom

${ }^{2}$ Science Policy Research Unit, University of Sussex, United Kingdom

${ }^{3}$ School of Geography, Archaeology and Irish Studies, National University of Ireland Galway, Ireland

${ }^{4}$ Consumer Society Research Center, University of Helsinki, Finland 


\title{
Alternative energy imaginaries: implications for energy research, policy integration and the transformation of energy systems
}

\begin{abstract}
The paper highlights shortcomings in the contribution of qualitative social sciences and humanities (SSH) research to tackling challenges connected with energy and climate change. These shortcomings are illustrated based on analysis of data gathered in relation to EU (e.g. Horizon 2020; FP7) and European national research funding and energy policy. The paper finds that a techno-economic energy imaginary continues to dominate European energy systems and governs expectations of energy research and its conduct, the integration of SSH with energy policy-making and the framing and foci of policy. A more nuanced, context-sensitive approach is presented as an alternative 'practices and cultural change' energy imaginary. This emphasises attention to social practices relevant to energy use, interdisciplinarity and the coproduction of knowledge with diverse actors. Adoption of such an imaginary can help to enhance policy integration of SSH and the contribution of SSH to ameliorating energy and climate change challenges while providing insight into why gaps occur between (supra)national energy policy and local practices.
\end{abstract}

Keywords: Energy imaginaries; energy research; grand challenges; Horizon 2020; Policy integration; Social Sciences and Humanities 


\section{Introduction}

This paper is inspired by the idea that there is a dominant techno-centric energy imaginary in Europe, which is the source of continuities that are inadequate to meeting prevailing energy and climate change challenges. The paper addresses two manifestations of this condition. First, there is the failure to appreciate the diversity of energy-related research and, in particular, to develop an imaginary of how qualitative social sciences ${ }^{\mathrm{i}}$ and humanities ${ }^{\mathrm{ii}}(\mathrm{SSH})$ research might contribute more effectively to energy policy-making in Europe and to transformation of energy systems. Qualitative SSH energy research aims to understand the place of energy in modern society, how and why people use energy and what it means to them and the 'culture' of energy, using a range of methods. The diverse approaches employed include participatory action research ${ }^{[1]}$, ethnography ${ }^{[2]}$ and role play ${ }^{[3]}$, often drawing on critical, constructivist and interpretive methodological perspectives. Qualitative SSH is typically less reliant on large-scale surveys, modelling and experimental research designs than energy research employed in quantitative social sciences or STEM (science, technology, engineering and mathematics) disciplines which draw on positivist methodological stances. The contribution of qualitative SSH energy research to energy policy-making in Europe is being overlooked and undermined, ${ }^{[4]}$ partly due to the institutionalisation of overly narrow conceptions of 'policy integration', and what should count as robust and policy relevant energy research. Policy-making organisations, including those which fund research, often emphasise the need for integration of research with policy, which can mean research engaging with problems as they are framed by policy actors. ${ }^{[5]}$ Integration with policy can also refer to the (re)presentation of research findings in particular ways that 'make sense' to policy-makers, calling into question the 'translation' of research for evidence-based policy. ${ }^{[6]}$

\footnotetext{
${ }^{\mathrm{i}}$ According to the Economic and Social Research Council in the UK, social sciences broadly concern: "the study of society and the manner in which people behave and influence the world around us". Social science disciplines include: Economics, Business and Management, Science and Technology Studies, Social Psychology, Sociology, Area and Development studies, Environmental Policy, Human Geography, Law and Politics. See: https://esrc.ukri.org/about-us/what-is-social-science/social-science-disciplines/

ii The Arts and Humanities Research Council's list of humanities disciplines includes: Archaeology, Classics, Cultural and Museum Studies, Development Studies, History, Information and Communication Technologies, Languages, Law and Legal Studies, Library and Information Studies, Philosophy, Political Science and International Studies, Theology and Divinity and Religion. There is overlap in this list with some social sciences. See: https://ahrc.ukri.org/funding/research/subjectcoverage/ahrc-disciplines/
} 
The second manifestation of the dominant energy imaginary foreshortens the contribution(s) that researchers are expected to make towards tackling grand challenges facing societies. From the point of view of research funders and university research management, enhancing the potential of research(ers) to make such contributions may be the subject of new institutional structures of research and impact assessment. ${ }^{[7]}$ Developing solutions to real-world problems may be promoted via targeted research funding programmes, cultural change or researcher training initiatives. ${ }^{[8]}$ However, such initiatives are devised on the basis of prevailing visions of what is desirable now and into the future, as well as framings of problems to be tackled and knowledge required. Thus such apparently novel designs remain rooted in the dominant energy imaginary which is inimical to the transformation of energy systems.

The adoption of an alternative energy imaginary is required to address the afore-mentioned shortcomings. This imaginary would have different foci than currently dominant techno-centric approaches - for example, targeting changes in social practices - and a methodological perspective prizing interdisciplinarity and co-production of knowledge with a range of diverse, active, stakeholders. Such thinking echoes wider developments regarding the governance of science and technology in society, notably that which concern the coproduction of scientific knowledge ${ }^{[9]}$, the 'opening up' of technological decision-making ${ }^{[10,11]}$ and responsible innovation. ${ }^{[12]}$ This paper contrasts dominant and proposed alternative energy imaginaries on the basis of data collected for a recently completed multi-country project ('ENERGISE') ${ }^{\text {iii }}$ funded by the European Commission Horizon 2020 initiative. The presentation of this new data significantly extends previous work published by the authors. ${ }^{[13]}$ iv Thus the authors are able to make a more fully developed contribution to understanding how SSH energy research might effectively influence energy policy-making in Europe, based on richer data and deeper analysis of problems of SSH - energy policy integration.

The paper investigates the following research questions:

a) What is the nature of the imaginary underpinning energy policy-making in Europe?

\footnotetext{
iii 'ENERGISE' - European Network for Research, Good Practice and Innovation for Sustainable Energy

iv This had addressed related issues but on the basis of textual analysis and, conceptually, was more limited.
} 
b) How is the imaginary implicated with integration of qualitative SSH energy research in Europe?

c) What kind of knowledge is energy research funded in Europe expected to contribute?

d) What country-level similarities and differences may be observed with respect to the above?

The paper is organised as follows. Section 2 discusses existing literature, arguing the need to analyse the dominant energy imaginary in Europe and a possible alternative imaginary relevant to the funding and conduct of SSH energy research and the integration of SSH with energy policy-making. Section 3 outlines the methods of data collection and analysis, whilst section 4 reports the findings from the study. Section 5 discusses the findings in the light of relevant literature. Section 6 concludes the paper, specifying the contribution it makes to advancing knowledge and policy and suggesting an agenda for future research.

\section{Integration of SSH with energy policy-making - an imaginaries perspective}

\subsection{From sociotechnical imaginaries to energy imaginaries}

Sociotechnical imaginaries are defined as 'collectively held, institutionally stabilised, and publicly performed visions of desirable futures, animated by shared understandings of forms of social life and social order attainable through, and supportive of, advances in science and technology'. ${ }^{[14]}$ Jasanoff et al. note that the 'term [sociotechnical imaginaries] itself is hybrid, straddling the humanities (imaginaries), social sciences (socio-), and science and technology studies (technical). ${ }^{[15]}$ Jasanoff and Kim state that: 'imagination helps produce collective systems of meaning that enable the interpretation of social reality'. ${ }^{[16]}$ Imagination is thus 'an organized field of social practices,' which operates in itself as a collective social fact, and 'serves as a key component in the making of social order'. ${ }^{[16]}$ 'Social imaginaries' encode 'collective visions of the [future and] good society...they reside in the reservoir of norms and discourses, metaphors and cultural meanings out of which actors build their policy preferences'. ${ }^{[16]}$ 
More directly than 'narratives', sociotechnical imaginaries serve an 'explanatory and justificatory' purpose, though they are considered to be less explicit and accountable than policy agendas. Instead they are 'instrumental and futuristic; they project visions of what is good and worth attaining'. ${ }^{[17,18]}$ Pfotenhauer and Jasanoff see sociotechnical imaginaries as informing locally co-produced understandings and implementation of universal models or 'best' practices, for example in the articulation and transfer of models of innovation cross-nationally. ${ }^{[19]}$

A growing literature is applying the concept of imaginaries to national energy technology policymaking, including studies of bioenergy in the UK, ${ }^{[20]}$ smart grids in Norway ${ }^{[21]}$ and Germany, ${ }^{[22]}$ and in developing countries. ${ }^{[23]}$ Supranationally, Kuchler analyses the global imaginary pertaining to second generation bioenergy. ${ }^{[24]}$ Others examine local urban imaginaries ${ }^{[25]}$ or regional imaginaries. ${ }^{[26,27]}$ These contributions recognise that local, 'everyday' talk and action may or may not influence national sociotechnical energy imaginaries 'upward' but likely affect how these are interpreted and acted upon, or not acted upon, locally. ${ }^{[28]}$

To research energy imaginaries as collective phenomena requires examination of the broad sweep of hopes, experiences and stories 'everyday’ people share about energy systems. These possible alternative images may appear as 'non-standard' when considered alongside expert-driven national imaginaries, as suggested by the ongoing Social Energy Atlas project (SEA). ${ }^{[27]}$ The scale of SEA is noteworthy, entailing interviews with a large, diverse and geographically dispersed sample of 1500 participants across the USA and collaborative networks of data sharing and management. SEA thus highlights research designs and possible alternative imaginaries of energy systems which might provide insight to policy-makers and others into why national energy policies fail. Strengers ${ }^{[18]}$ distinguishes 'social practice imaginaries' from dominant approaches to imagining energy futures which take technology as an entry point to changing how people live. Her work emphasises everyday practices (e.g. pertaining to pet care or telework) as the cornerstone for developing scenarios for transforming energy use, informed by post-humanist methodologies. Further, social scientists are important stakeholders in identifying and developing scenarios relevant to energy policy-making, their grounding in ethnographic and other qualitative methods coming to the fore. ${ }^{[18]}$ 
Overall, this review of recent research relevant to energy imaginaries leads to the following observations which inform the framework presented in section 2.3:

a) much research has focused on state energy imaginaries and expert-driven views thereof, which tends to neglect the 'underlying messiness' of, and variation in, energy imaginaries;

b) this messiness and variation can be grasped more effectively by studying 'multivalent' stories in local places, ${ }^{[29]}$ though studies of national energy imaginaries may highlight what visions of the public(s) are being employed and acted upon by policy-makers, technical experts and researchers (c.f. Cherry et al. on 'imagined publics'); ${ }^{[30]}$

c) temporality needs to be addressed, for example in connecting multiple, competing or complementary energy imaginaries at different scales to developing energy innovation pathways ${ }^{[20]}$ and in considerations of what 'ought to be'; ${ }^{[31]}$

d) supranational and sub-national phenomena are both promising sites for inquiry; and

e) there is insufficient attention to what makes certain configurations of society and energy technology unimagined or unimaginable. ${ }^{[32]}$

\subsection{Integration of SSH energy research as a problem of imaginaries}

There are various accounts of the lack of integration of SSH with energy policy, though fundamentally the source of the failure is implicated with the enactment of a dominant imaginary of the energy system. Due to 'disciplinary chauvinism' SSH are only accorded a secondary role in energy research in the EU, compared with the natural sciences. ${ }^{[33,34]}$ This reinforces a tendency to under-emphasise social 'dimensions' of energy in favour of the technical and the material. ${ }^{[34]}$ Further, even where the social does enter, it is typically through 'scientistic' approaches which mirror the research strategies pursued in STEM disciplines or adopt a narrow conception of behaviour. Fundamentally, then, questions are tackled within a dominant framing of energy and climate change problems as rooted in changing individual attitudes, behaviour and choices. ${ }^{[35]}$ Relatedly, the treatment of SSH in energy research in Europe betrays certain misconceptions; for example, the 
variety of and differences between SSH approaches and foci are missed as the plurality of SSH goes unrecognised. ${ }^{[36]}$ A lack of appreciation of the nature and variety of methodological approaches and research methods employed by researchers from different SSH perspectives and disciplines exacerbates the problem.

Integration of SSH energy research with energy policy-making has been the object of much discussion, taking in considerations of the impact of research on policy and the ways in which research findings are used in policy-making, but also how such work is co-produced. In the specific context of the EU, one needs to appreciate such integration in broader scope, as the coordination between EU energy and non-energy policies and between national and EU policy-making have themselves been problematic. Here, SSH integration with policy is often addressed as part of wider debates on energy transitions, socio-technical systems design, and discussions about the role of SSH in interdisciplinary (energy) research. ${ }^{[37,38,39,40]}$ One of the biggest challenges for qualitative SSH is to produce research that is recognised as having an impact on policy and practice. In energy-related research, the failure of SSH to influence governmental decisions (and transform energy systems, more generally) has been argued to be its limited use of physical science, i.e. reference to physical units in social studies of energy. ${ }^{[38]}$ It has also been suggested that SSH energy research is often perceived as 'unrealistic' because what counts as realistic is too narrowly defined in the current policy arena. ${ }^{[39]}$ An understanding of the policy arena as differentiated and 'stretched out', extending way beyond government, can produce a broader and deeper understanding of the potential contribution of SSH. ${ }^{[39]}$

Policymakers sometimes have exaggerated expectations of what SSH can do, what policy relevance means in the short- and long-term, and what it means to SSH researchers. ${ }^{[37]}$ The crucial distinction between actors such as policymakers, advisors, and politicians who are licensed to make quick judgements on at best imperfect evidence (in the era of 'evidenced-based policy'!), and professional SSH which cannot come up with anything 'quickly' on a new or unfamiliar problem, adds to the differences between two distinct cultures. ${ }^{[7]}$ Besides, policy relevance often means that research should have some applicability to the reduction of uncertainty about the course of future events. Thus, 
what is often requested of SSH is some form of prediction given some physical or technical scenario, which can be difficult, if at all possible to achieve. ${ }^{[37]}$

A clearer understanding of what SSH can and cannot contribute, and what level of resources and involvement are required, would help to make SSH integration with policy more efficient and satisfying for both communities. Stern suggests that although the openness of policy to SSH research partly depends on the mindset of the policy audience, policymakers are more open to social science input when issues cannot be addressed with available tools. ${ }^{[40]}$ A recent paper in Energy Policy by two members of the European Commission Joint Research Centre's unit for Energy Efficiency and Renewables highlights the limits of EU energy policy approaches to energy conservation focusing on energy efficiency and behaviour change of individuals, informed by quantitative analyses. ${ }^{[41]}$ Instead, they suggest, more nuanced understanding of everyday energy demand-related social practices is required, such as might be gained by applying qualitative $\mathrm{SSH}$ to their analysis and the design and implementation of policy instruments based thereon. Shove takes this further, stressing that what is 'wrong' with a policy focus on energy efficiency is its tendency to remove from view what energy is for as well as to reproduce notions of use and service which are ultimately unsustainable, thus rendering energy efficiency measures ineffective, if not counter-productive. ${ }^{[42]}$ An alternative imaginary entails novel ways of seeing research objects, subjects and relations among them, with citizens, policy-makers, industry actors and researchers as partners in the co-production of knowledge about everyday practices in energy systems.

The discussion here suggests that sociotechnical imaginaries is a perspective which may help to enhance understanding of the integration of SSH with energy research and policy-making. One may renew and employ the imaginaries concept ${ }^{[43]}$ to generate a more fundamental critique of SSH energy research, EU and European national energy policy and integration of energy research with policy. Such a critique could embrace the ways in which energy system problems are framed in relation to risks, the nature and 'closure' of energy controversies and (visions of) the roles played by civil society and technological innovation. The following sub-section presents an analytic framework informed by 
the discussions above. This framework governs the data collection and analysis reported in the remainder of the article.

\subsection{A framework for the analysis of energy imaginaries}

Table 1 identifies and compares two possible imaginaries of energy systems ('energy imaginaries').

${ }^{[13]}$ Each energy imaginary represents a worldview of energy research and its integration with energy policy, through which the nature, proper conduct and potential impact of SSH is envisioned and substantiated within processes governing energy generation, supply and consumption. The left-hand column identifies six dimensions of a 'technological and behaviour change' energy imaginary. Here, the fundamental challenge to be confronted may be summed up as the need to find the best technical solutions or behaviour change approaches that can contribute to reducing carbon emissions from energy use and generation. Risks are framed in terms of the technical challenges that have to be overcome and the need for social acceptability of (e.g. renewable energy) technologies and behaviour change programmes. Relatedly, what is at stake and ensuing controversies concern the extent of climate and energy-related difficulties and the necessity for renewable, low carbon or energy efficient technology measures being proposed as well as their impact on economic development, competitiveness and consumer choice. 'Closures' take the form of authoritative governmental policies or legal decisions (e.g. national climate change legislation, planning decisions or international agreements).

The right-hand column of Table 1 represents an alternative energy imaginary, labelled 'practices and cultural change'. This imaginary does not predominate European energy systems but is beginning to gain purchase in energy policy and research discourses, if not fully articulated. In this imaginary, social practices connected with energy use, and the spatial and temporal configuration of local/ national/supranational energy talk and action supplant the techno-centrism and national policy focus of the dominant imaginary outlined above. The alternative imaginary may not be mainstream but, arguably, evidence of it can be found in certain recent activities and networks involving a range of actors. ${ }^{[18,27,44]}$ Here, risks are framed primarily in terms of technological failure and the need to understand energy-related cultures assuming that investment in technology development per se may 
not achieve the required reductions in energy use and carbon emissions. Table 2 illustrates the mundane material, symbolic and knowledge dimensions of cultures relevant to energy use, implicated with shared practices of keeping warm at home. The policy focus in the alternative energy imaginary is to achieve changes in energy-related practices (e.g. related to mobility, heating, lighting, cooking, etc.), with an emphasis on 'bottom-up' governance i.e. recognising that energy users play a far more active role in shaping the energy systems than has typically been thought. ${ }^{[4]}$ One of the controversies entailed in this policy focus concerns the emphasis on people changing routine aspects of how they live, implicated with conventional use of energy in the home. At stake in this imaginary is how to realise genuine co-creation of knowledge among professional researchers, policy-makers, the public(s) and others, capable of changing energy practices, shaping future research agenda and effectively making an impact on the substance and process of national or EU energy policy. Closures in the alternative imaginary may take the form of policies and legislative decisions justifying particular pathways of development, but these remain open to local and wider reinterpretation, challenge and disruption. Examples include localised energy, food and agriculture production and consumption, in which the imaginaries of protagonists are likely more about preferred approaches to social organisation and lifestyle than compatibility with national energy and technology policy.

\section{[TABLE 1 ABOUT HERE]}

\section{[TABLE 2 ABOUT HERE]}

\section{Methodology}

To answer the research questions, the researchers collected data from a range of primary and secondary sources in three phases. In Phase 1 (August-September 2017), the researchers reviewed research and grey literature pertaining to the potential and actual contribution of SSH to EU energy research and policy-making. Open, online EU databases permitted access to relevant documents and data on energy research funding. ${ }^{\mathrm{v}}$ Phase 1 activities helped build up a picture of the context of EU energy research funding and policy-making and expectations of SSH research, setting the scene for

\footnotetext{
${ }^{v}$ The main information sources are European Commission and European Research Council resources available online (https://ec.europa.eu/, https://erc.europa.eu/).
} 
Phase 2 which sought to understand the priorities of specific EU funding calls and programmes. In Phase 2 (March 2018), the authors searched the aforementioned databases for data on the content of funding calls associated with the FP7 and Horizon 2020 energy work programmes and the level and nature of projects funded thereby. Phase 3 entailed the collection of data on SSH integration with energy-related policy making at national level in eight European countries: Denmark, Finland, Germany, Hungary, Ireland, Netherlands, Switzerland, and the UK, assisted by research consortium members (December 2017-April 2018); feedback was obtained from policy-makers and practitioners at a workshop (held in June 2018).

Data collected in Phase 3 comprised: (1) desk-based research undertaken by members of the ENERGISE consortium in each country (national policies, national funders' databases, publicly funded research programmes/calls in the last 10 years); and (2) reporting of data in a structured, consistent manner, using a template and methodological guidance provided for data collection and reporting. To illustrate the state of the art of SSH integration with energy policy in those countries, the researchers gathered data on: (a) use of research knowledge and evidence in policy making; (b) sources of funding for energy research, funding policies, details of specific funding calls for energyrelated SSH research; and (c) information about funded projects. As the members of the consortium have extensive experience in the field of energy and sustainability research, the data collected was supplemented by researchers' reflections on their experience of, and views on, challenges to better integration of SSH energy research with policy.

The authors analysed the approaches adopted to utilisation of SSH knowledge within national energy policy-making, national research funding priorities and policies and energy-related projects funded at the national level. They identified similarities and differences among the countries investigated, to illustrate the state of the art of SSH integration with energy research and policy-making in the aforementioned countries. In interpreting the findings the authors considered the relevance to the different dimensions of the energy imaginaries framework presented in Table 1. 


\section{Findings: the funding and policy integration of SSH energy research in Europe}

This section considers the funding and integration of SSH within energy research supported by the European Commission through the last two of its framework funding programmes: FP7 (2007 - 2013) and Horizon 2020 (2014 - 2020). It then presents data from a survey of ENERGISE researchers on the integration of SSH with energy research and policy-making in Europe.

\subsection{SSH integration within European Commission and H2020 funded energy research}

This sub-section considers the standing of SSH energy research within overall EU energy funding. In relation to SSH, FP7 funding over 2007-2013 constituted the largest allocation in the world for SSH research. However, an ex-post evaluation of FP7 comments on the relatively low share of funding enjoyed by the dedicated 'socio-economic sciences and humanities' sub-area of COOPERATION. ${ }^{[45]}$ SSH accounted for the lowest shares of projects and funding within 'COOPERATION', gaining only $1.3 \%$ of the programme's total budget (although in relation to share of funding from the FP7 IDEAS programme, $15 \%$ of ERC grants were awarded to SSH disciplines). Proportionally-speaking there were more small and medium-sized projects in the SSH sub-area than for others within the FP7 COOPERATION programme. 'Economics and other social sciences are the most reported main or associated discipline, while Humanities disciplines represent only a small share'. ${ }^{[45]}$ In the period 2007-2018, which covers the duration of FP7 and roughly the first half of Horizon 2020, SSH won a share of just over $20 \%$ of projects funded by the ERC (see Table 3, below). More specifically, energySSH comprised 41 of 1354 ERC-funded energy projects, a proportion of just over 3\% (Note that here the data for 'energy-SSH' includes cross- or interdisciplinary projects having an SSH component).

\section{[TABLE 3 ABOUT HERE]}

An interim review of the first three years of Horizon 2020 (2014-2016) states that SSH comprised $12.9 \%$ of signed grants, representing funding of EUR 4.4 billion. ${ }^{[46]}$ Moreover, only a third of projects funded under topics flagged for SSH show good integration of SSH, while integration was absent from another third of such projects. The interim review found that Horizon 2020 could involve citizens more in shaping and implementing projects. 
A Commission report on SSH integration in SSH-flagged projects funded in 2017 by Horizon 2020 under the societal challenges and industrial leadership priorities notes the almost 'non-existence' of disciplines such as Anthropology and Geography in comparison with 'harder' SSH such as Economics. ${ }^{[47]}$ The same report applies four indicators to denote integration of SSH across and within Horizon 2020. These indicators are: share of project partners listed in grant agreements denoted as having significant expertise in SSH; budgets of the 'SSH partners' in funded projects; contribution from thirteen SSH disciplines; and person-months performed by SSH staff. The quality of integration on a 'low threshold' requires a score of $10 \%$ in the first three aforementioned criteria and the involvement of two SSH disciplines. 'Good' quality integration for a project would meet all four threshold criteria, whilst 'weak' integration would satisfy only one criterion. In 2017, the Horizon 2020 societal challenge on secure, clean and efficient energy ('SC3') 56\% of SSH-flagged projects had no integration and 21\% had 'good' integration of SSH. In comparison, for SSH-flagged societal challenge and industrial leadership Horizon 2020 projects as a whole, $21 \%$ of projects had no integration and 55\% had 'good' integration using the 10\% threshold. Using a stronger $20 \%$ threshold, $80 \%$ of SC3 projects funded in 2017 have no or weak SSH integration and $18 \%$ have good integration. ${ }^{[47]}$ This is in spite of recent demands to take greater account of SSH in energy research. Overall, there is a sense of SSH being necessary yet subordinate to science and engineering, while cross-disciplinary research is sought after but impeded by the inability of STEM researchers to value properly or make sense of knowledge generated through $\mathrm{SSH}$. The next subsection considers the issues as they apply to national level support for SSH energy research and its integration with policy.

\section{$\underline{4.2 \mathrm{SSH} \text { integration in European energy research and policy }}$}

\subsubsection{Funding policies for SSH research in Europe}

To understand the lack of impact of SSH on energy policy in Europe the authors examined the nature and implications of funding policies. ${ }^{\text {vi }}$ The amount of funding available for SSH energy research at

\footnotetext{
${ }^{v i}$ Contract/commissioned research (which aims primarily to inform policy following a tender process) is not included in this review. The focus is on those public funders in each country which provide support for SSH research with an academic purpose (though this may still have policy relevance or impact).
} 
the national level differs dramatically among the eight countries studied (Table 4, below, gives details of public funders of energy-related research in selected countries).

\section{[TABLE 4 ABOUT HERE]}

For some countries it is possible to identify several levels and several streams of public funding for SSH research. For example, research and development in the UK is funded by the government, by companies, and by charitable organisations. Two main streams of research funding coming from the government exist in the UK (and other countries): (1) government departments (research commissioned for policy and practice); and (2) research councils and other research funding bodies that support research in academia and sponsored by the government (academic research that also creates impact). There are also many partnerships between government departments and the research councils.

Germany provides a good example of two levels of funding in public energy research - national (by individual federal ministries) and regional (by the provincial states). Provincial funding accounts for about one third of publicly funded non-nuclear energy research. Project funding is carried out often as co-financing with the European Regional Development Fund.

Public funding opportunities for energy SSH research is often derived from and linked to politics and have fundamental political decisions behind them. For instance, energy research is an important pillar of energy policy in Switzerland and is explicitly defined as one of the strategic cornerstones of the federal government's 'Energy Strategy 2050'. The National Research Programmes NRP70 and NRP71 have the main objective to propose potential solutions that can be implemented in Switzerland in the coming 10 to 30 years.

Private funding can play a significant role in supporting SSH energy research, e.g. private foundations in Denmark who fund environmental, sustainability and energy-related research, including SSH (e.g. the Velux Foundations including Villum Foundation; KR Foundation). Another example is the Mercator foundation in Switzerland, a private foundation that supports research on environmental issues, especially on sufficiency. However, the scarcity of funding for SSH research compared with 
technical sciences is obvious, even in the countries with multiple funding opportunities and significant amount of support available for SSH research. For example, the differences in budget allocations for the technical and socio-economic calls by SNSF in Switzerland are dramatic - funding for technical research received almost five times more. Moreover, public funding for energy research seems to have declined substantially in the last decade. In Hungary both funding possibilities for and the practice of energy-related SSH research are very limited. There is no central policy for its support, thus, the funding landscape is very fragmented.

In most of the eight countries, SSH energy research is funded under general open funding calls and sometimes under special thematic calls/programmes (SSH or interdisciplinary). In countries like Denmark, Finland, Hungary and Netherlands there are no specific energy-related funding calls for SSH disciplines. In Denmark, it is common for SSH to be subsumed into some calls for strategic research and technical research programmes (e.g. this is the case for research related to smart grid innovations). The Strategic Research Council in Finland also promotes interdisciplinarity with the aim to involve SSH in environmental and energy research as part of interdisciplinary calls/programmes. Additionally, other funding bodies prioritise interdisciplinarity and responses to grand challenges (e.g. the Academy of Finland programme 'New Energy'; Sitra's theme 'Carbonneutral Circular Economy'). The multi-disciplinary/interdisciplinary approach for funding energy research is also common in Netherlands. There have been a limited number of energy-related funding calls/programmes that were open to SSH (e.g. Joint Scientific Thematic Research Programme between China and Netherlands 'Smart Energy in Smart Cities' in 2014, 'The Energy Transitions programme' in 2010, 'Sustainable Living Labs' in 2018). Although the programmes are not designed solely for SSH, they leave some scope for incorporating a social science component alongside applied/technical sciences and natural sciences stimulating 'innovative multi-disciplinary research'. The open research calls funded by the National Research Development and Innovation Fund in Hungary provides funding opportunities for researcher-initiated energy SSH projects. Similarly, the Irish Research Council funds energy SSH projects under open calls. The Irish Environmental Protection Agency does not have an 'energy' strand and specific calls for SSH energy research, but it 
can fund energy-related SSH projects under the sustainability research umbrella. The Sustainable Energy Authority of Ireland 2018 funding call includes two topics that could be related to SSH research, although the two projects funded by SEAI are classified as small-scale projects with a 'traditional' focus (i.e. on socio-economics and behaviour change). Other countries (Germany, Switzerland, and the UK) have pronounced funding programmes/calls for energy-related SSH, which are often addressed as part of broader sustainability programmes.

\subsubsection{Energy research projects in European countries}

The overview of the national publicly funded projects is based on a selection of significant SSH energy research projects (or interdisciplinary projects which are largely SSH based), funded at the national level by public funders during the period 2008-17 and related to domestic energy consumption (up to ten projects selected per country). For countries with a very limited number of such projects, a broader theme of domestic energy (e.g. energy efficiency), energy consumption, and/or sustainable energy was used to produce a list. The search was conducted in 2018 using publicly available online funders' databases, such as the UK Research and Innovation gateway to publicly funded research - gtr.rcuk.ac.uk (now gtr.ukri.org) and Danish Research, Development and Demonstration Funding Programmes within Energy and Climate (energiforskning.dk).

The aggregated list comprised 62 research projects (including funded research networks). Although the list is not exhaustive, it is illustrative of SSH research funded by national public funding bodies in the area of sustainable energy and domestic energy consumption in eight countries. ${ }^{\text {vii }}$

More than half of all projects (32) are interdisciplinary involving collaboration between SSH and STEM researchers, although there are some variations between the countries. For example, the Finnish and German projects are primarily interdisciplinary (a mix of STEM and SSH), as only few projects related to energy-research seem to be pure SSH; technology or engineering aspects are almost always a part of energy projects. Only four research projects that are SSH based were identified in Ireland, as almost all funded research in the energy sphere is STEM based. This illustrates the

\footnotetext{
vii The list of national research projects is available at: energise-project.eu/sites/default/files/content/ENERGISE_D6.4_300518_FINAL.pdf
} 
tendencies in national research funding policies that prioritise technical research over social science in the area of energy and funders promoting interdisciplinary calls/programmes. Similarly, the prevailing methods of research mirror preferences of public funders. Only around 14.5\% (9) of the projects from the list rely on qualitative research methods (solely or primarily); 16\% (10) employ quantitative methods, and the remaining are reported as using mixed methods.

SSH disciplines are mainly represented by Economics (including Political Economy, Economic Sociology, and Behavioural Economics), Sociology (including STS), Psychology, Political Sciences, and Geography (including Human Geography and Environmental Planning). ${ }^{\text {viii }}$ This corresponds to findings in the literature about funders' preferences for economic and behavioural sciences in energy research. ${ }^{[38,40]}$

The most commonly studied phenomena are: sustainable or energy transitions; energy consumption practices and energy savings in households; social aspects of energy-related innovation/technology; sustainable communities and citizen-driven innovation; low carbon technologies and renewable energy; and energy poverty.

The differences in national funding policies and availability of research funding affects the number and the focus of research projects (that also vary in scope and scale), as well as the expected policy relevant outcomes. The importance of addressing policy makers as one of the key audiences is not always recognised in the research projects funded at national level, reducing the potential for integration of research findings with policy, although this differs among eight countries. Only around half of all research projects claim explicit policy relevance or, in some cases, impact. This can take the form of concrete steps towards incorporating research findings into policy papers and strategies and specific recommendations for policy-makers, as well as direct engagement or collaboration with government bodies and policy makers. This is more common for research projects in the UK, but also applies to Ireland, Switzerland, Finland, Netherlands and Germany. Among them a significant number of projects have an aim to inform local policy makers and practitioners contributing to e.g. energy campaigns or sustainable transitions at the city or municipality level.

\footnotetext{
viii The list starts with more common disciplines.
} 


\subsubsection{Social scientists' perspectives on SSH integration with policy}

Social scientist respondents who took part in the study perceive challenges relating to research projects' implementation and further dissemination and impact as including: problems of continuity of funding for SSH research; limited and patchy utilisation of research results by policy; problems of effective communication with policy and other decision makers and timely dissemination of results, which is partly due to the nature of ( $\mathrm{SSH}$ ) research findings; impact assessment of research; the status of social science within policy and political circles; and the politicisation of research.

Respondents made some suggestions for better integration of SSH research with policy and practice. One of the key points made addresses the research community itself - mobilising a large number of researchers promoting similar or compatible agenda would potentially make SSH research more 'influential'. Whilst it may provoke conflict among researchers and policy makers and practitioners, and possibly detract from impacting policy, social science should enjoy its 'public' and political role advocating their research agenda, mindful of the duty to help produce the best 'evidence' possible in relation to fundamental questions and challenges society faces. Here, a tradition of public engagement in research can enhance the transformative potential of research. On the other hand, promoting practical and proven solutions demonstrating utility of SSH research rather than just problematising issues without solving them would make SSH research more 'appealing' and useful for the public, policy makers and practitioners. It is emphasised that new forms of knowledge co-production are needed, where researchers, administrators, politicians and other stakeholders work together to solve real-life problems and build up a shared knowledge community or epistemic culture. For instance, multi-stakeholder events with a dedicated interactive element (forums, workshops, etc.) are very useful for sharing and discussing SSH research and evidence, as are media appearances and dissemination channels reaching beyond academia. On the other hand, new and innovative forms of impact assessment are needed that could capture the complexity of the short-, medium- and long-term effects of research, including its actual impact on the policy realm and the societal processes. 


\section{Discussion}

The data presented above underline the primacy of STEM disciplines in energy research, with SSH assuming at best a complementary role in European national and EU-funded research. Where SSH is present, disciplines related to Economics predominate, and qualitative approaches occupy a minor position. The influence of SSH on national policy relating to energy and environment matters seems either a) to be concentrated (again) mainly within the discipline of Economics; or b) is only indirect. These findings accord with what is already known about the role of SSH in energy research. ${ }^{[33]}$

One might understand the dominant modes of interdisciplinarity ${ }^{[19]}$ in EU-funded and European national energy research as the subordination of SSH to STEM disciplines. In relation to interdisciplinary energy research, there is an emphasis on increasing economic competitiveness through innovation - albeit 'green'. This position has evolved within neo-liberal processes in which the benefit to society of such activities is identified with 'responsible innovation' ${ }^{[12]}$. STEM disciplines play a primary role in delivering such innovation to the market place. The paper confirms that SSH typically takes a secondary place within time-constrained projects as a complement or service to 'balance' STEM activities. SSH tends not to play an antagonistic role. European Commission and EU nations' funding structures have not generally developed in such a way as to permit or to enable such a function.

In this regard, energy imaginaries may be applied to add insight into the question of why SSH plays supportive or complementary roles to STEM disciplines in European energy research, rather than ones of leadership and critique. The prevailing situation owes much to an imaginary in which policymakers and funders understand energy challenges as fundamentally technical in character. The role ascribed to society in this framing of energy policy challenges is to accept and adopt new energy efficiency-related technologies. The paper does provide some evidence to the contrary, particularly with regard to examples from UK and Finland. This may be due in part to the institutionalisation of the impact culture and interdisciplinarity in national research assessment and funding. However, such developments do not yet amount to an embedding of the alternative imaginary described in the right- 
hand side of Table 1, rather they appear more as a marginal adaptation to the conventional technocentric imaginary.

The findings support the argument that the focus of energy policy in Europe is underpinned by a concern to promote and diffuse energy efficiency and 'low carbon' or renewable energy generation technologies. This tendency is more prevalent than an emphasis on nurturing bottom-up governance of energy, or on identifying and changing practices of everyday energy use. One might interpret the prevalent focus of energy policy in terms of what appears to policy-makers to be at stake. EU and national policy-makers and funders tend to justify energy policies by reference to the need to be competitive in the developing market for sustainable technologies and to the role of innovation in fulfilling this requirement. There is both a supply and demand aspect to this, so that securing the buyin of 'consumers' (note, not 'people' or 'citizens') is a necessary parallel concern that is at stake. Following this line of argument, what becomes controversial in the prevailing energy policy imaginary are the attitudes of consumers and the choices that they make. As recognised previously, this gets entwined with the question of how to achieve behaviour change, typically from the 'top' down. This, in turn, invites debates about the possibly overbearing nature of state action and interference with consumer choice but not about fundamental practices associated with using energy at home. ${ }^{[18]}$ To the extent that these come into view, they enter the scene in relation to energy bills, for example how they might be lowered if smart meters are installed and consumers were made more aware of consumption levels for the household of individual appliances. This is a long way from the co-creation of knowledge about practices suggested by the alternative energy imaginary. The data exemplifies the prevailing imaginary with regard to the role that formal policies and measures play in (attempts to) resolve climate change and energy problems. In Europe, climate change legislation and targets set the scene for commitments on research funding and other support for science and innovation directed at providing solutions for centrally prescribed problems. These may be influenced by social scientific knowledge, lobbying or grassroots movements but in a manner that rehearses the dominant imaginary, emphasising formal rules, technological innovation and building awareness in order to elicit behavioural change. What the data does not show is a predisposition of policy makers 
and funders to appreciate spaces inhabited by energy imaginaries in which culture and practice are written and rewritten into everyday use of energy.

The evidence relating to national funding of SSH energy research shows that integration of qualitative social science pertains to the generation of potential solutions to problems defined by funders and policy-makers, contributing to the instrumental design of policy mixes. ${ }^{[48]}$ It also pertains to the development and understanding of participatory processes of policy-making that might effectively engage citizens in energy matters to promote behaviour change. There are methodological implications of both of these modes of integration, concerning the generation and use of knowledge in different imaginaries of energy, the politics of the 'participatory turn' and of the translation of knowledge relevant to energy policy-making. The 'participatory turn' indicates the institutionalisation of the co-production of knowledge among a range of societal actors. ${ }^{[9]}$ However, it remains questionable just how genuinely collaborative such approaches are as applied in practice. It is arguable that processes are not as open to shaping from citizens as they could be and that funding processes militate against this. Further, the continuity of the prevalent energy imaginary is ensured when even the research that is most intent on working collaboratively with citizens and other stakeholders jointly to understand everyday practices considers it advantageous to present findings to policy-makers in the most (currently) conventional ways. Thus, projects which have been geared towards the identification and promotion of alternative ways materialising energy have found it expedient to present the quantifiable elements of their findings or to reduce the nuance of the research to more digestible 'bullets' for policy-makers.

\section{Conclusion}

This paper aimed to improve understanding of the nature and extent of integration of qualitative social sciences and humanities (SSH) with EU energy research and policy and in individual European countries. To this end, the authors analysed data collected on integration of SSH with EU energy research and policy and in eight selected European countries. They found that the prevailing approach to policy integration undercuts the deeper impact that SSH energy research may have on shaping policy and on governance in a broader sense (energy politics as distinct from energy policy). Prior 
work had identified contributory factors such as the application of weak conceptions of policy integration and barriers to interdisciplinarity, which failed to realise the potential of SSH. What this paper has done is to recontextualise these arguments by appealing to a notion of 'energy imaginaries', informed by the sociotechnical imaginaries approach. Although the energy imaginaries concept is not a completely new one, the authors argue that its deployment as a sensitising concept harnessing thinking about energy policy framing, interdisciplinarity, research methodology and relations among diverse energy actors is novel and informative.

To invoke energy imaginaries is to look to the future in such a way as to govern contemporary practice. Thus the findings presented above attest to how visions of what is necessary to transform energy systems to meet identified energy challenges are mirrored in contemporary decisions and worldviews held by spatial or practice communities of influential actors. Imaginaries are materialised as individuals talk and act with others about energy. This applies to European Commission energy policy and research funding and to similar phenomena in European countries. However, energy imaginaries are not totalitarian. There are exceptions to the national picture and local energy imaginaries. These point to other possibilities for energy systems, which the alternative 'practices and culture change' energy imaginary attempts to capture and which the prevalent techno-centric imaginary does not.

The next step is to refine the energy imaginaries framework presented here, for example on the relation between openness and closure in the alternative imaginary. Future research should extend the empirical aspect of the study, by considering a larger sample of countries and obtaining more extensive data on national energy research funding and policy, local imaginaries and the level and nature of SSH integration with the foregoing. Fundamentally, SSH has an important role to play in informing energy policy but also in advancing new patterns of relations among diverse actors within an alternative energy imaginary which transforms the foci, conduct and governance of EU energy policy-making and research and that of individual European countries. 


\section{Acknowledgment}

The research reported in this paper was funded by the European Commission Horizon 2020 research and innovation programme under grant agreement 727642.

\section{References}

[1] Gailing, L., M. Naumann (2018). Using focus groups to study energy transitions: Researching or producing new social realities? Energy Research \& Social Science, 45, 355-362,

[2] Goodman, J. (2018) Researching climate crisis and energy transitions: Some issues for ethnography. Energy Research \& Social Science, 45, 340-347.

[3] Thomas, M.T. Partridge, N. Pidgeon, B. Herr Harthorn, C. Demski, A. Hasell (2018).

Using role play to explore energy perceptions in the United States and United Kingdom,

Energy Research \& Social Science, 45, 363-373.

[4]. Foulds C., R. Robison, 2018. Mobilising the Energy-Related Social Sciences and Humanities. In: Foulds C., Robison R. (Eds.) Advancing Energy Policy. Cham: Palgrave Pivot, 1-11.

[5]. Lindberg, M. B., Markard, J., A.D. Andersen, 2019. Policies, actors and sustainability transition pathways: A study of the EU's energy policy mix. Research policy, 48(10), 103668.

[6]. Luukkonen, T., M. Nedeva, 2010. Towards understanding integration in research and research policy. Research Policy, 39(5), 674-686.

[7]. Rau, H., G. Goggins, F. Fahy, 2018. From invisibility to impact. Recognising the scientific and societal relevance of interdisciplinary sustainability research. Research Policy, 47, 266-276.

[8]. Leahey, E., S.N. Barringer, 2020. Universities' commitment to interdisciplinary research: To what end? Research Policy, 49(2), 103910. 
[9]. Gibbons, M., C. Limoges, H. Nowotny, S. Schwartzman, P. Scott, M. Trow, 1994. The New

Production of Knowledge: The Dynamics of Science and Research in Contemporary Societies. Sage, London.

[10] Stirling, A., 2008. "Opening up" and "Closing down"-power, participation, and pluralism in the social appraisal of technology. Science, Technology and Human Values 33: 262-294.

[11] Stirling, A., 2014. Transforming power: Social science and the politics of energy choices. Energy Research \& Social Science, 1: 83-95.

[12] Owen, R., Bessant, J., Heintz, M. (Eds.), 2013. Responsible Innovation: Managing the Responsible Emergence of Science and Innovation in Society. Wiley, London.

[13]. Genus A., F. Fahy, G. Goggins, M. Iskandarova and S. Laakso, "Imaginaries and Practices: Learning from 'ENERGISE 'About the Integration of Social Sciences with the EU Energy Union”. In C. Foulds, R. Robison (Eds.) Advancing Energy Policy. Cham: Palgrave Pivot, 131-144.

[14]. Jasanoff, S., 2015. Future Imperfect: Science, Technology, and the Imaginations of Modernity. In S. Jasanoff, S.-H. Kim (Eds.). Dreamscapes of Modernity: Sociotechnical Imaginaries and the Fabrication of Power. Chicago, IL: University of Chicago Press, 1-33.

[15]. Jasanoff, S., S-H Kim, S. Sperling, 2007. Sociotechnical Imaginaries and Science and Technology Policy: A Cross-National Comparison. Project proposal submitted to National Science Foundation.

[16]. Jasanoff, S., S-H Kim, 2009. Containing the atom: sociotechnical imaginaries and nuclear power in the United States and South Korea. Minerva, 47: 119-146.

[17]. Sovacool, B. K., D.J. Hess, 2017. Ordering theories: typologies and conceptual frameworks for sociotechnical change. Social Studies of Science, 47(5): 703-750. 
[18]. Strengers, Y., S. Pink, L. Nicholls, 2019. Smart energy futures and social practice imaginaries: forecasting scenarios for pet care in Australian homes. Energy Research \& Social Science, 48: 108115.

[19]. Pfotenhauer, S., S. Jasanoff, 2017. Panacea or diagnosis? Imaginaries of innovation and the "MIT model' in three political cultures. Social Studies of Science, 47(6): 783-810

[20]. Levidow, L., T. Papaioannou, 2013. State Imaginaries of the Public Good: Shaping UK Innovation Priorities for Bioenergy. Environmental Science and Policy, 30: 36-49.

[21]. Ballo, I., 2015. Imagining energy futures: Sociotechnical imaginaries of the future Smart Grid in Norway. Energy Research \& Social Science, 9: 9-20.

[22]. Engels, F., A.V. Munch, 2015. The micro smart grid a materialized imaginary within the German energy transition. Energy Research \& Social Science, 9: 35-42.

[23]. Delina, L.L., 2017. Whose and what futures? Navigating the contested coproduction of Thailand's energy sociotechnical imaginaries. Energy Research \& Social Science, 35: 48-56.

[24]. Kuchler, M., 2014. Sweet dreams (are made of cellulose): sociotechnical imaginaries of secondgeneration bioenergy in the global debate. Ecological Economics, 107: 431-437.

[25]. Tozer, L., N. Klenk, 2018. Discourses of carbon neutrality and imaginaries of urban futures. Energy Research \& Social Science, 35: 174-181.

[26]. Schelhas, J., S. Hitchner, P. Brosius, 2018. Envisioning and implementing wood-based bioenergy systems in the southern United States: imaginaries in everyday talk. Energy Research \& Social Science 35: 182-192.

[27]. Smith, J.M., A.S.D. Tidwell, 2016. The everyday lives of energy transitions: contested sociotechnical imaginaries in the American West. Social Studies of Science, 46, 3: 327-350.

[28]. Levenda, A.M., J. Richter, T. Miller, E. Fisher, 2019. Regional sociotechnical imaginaries and the governance of energy innovations. Futures, 109: 181-191. 
[29]. Tidwell, J.H., A.S.D. Tidwell, 2018. Energy ideals, visions, narratives, and rhetoric: examining sociotechnical imaginaries theory and methodology in energy research. Energy Research \& Social Science, 39: 103-107.

[30]. Cherry C., C. Hopfe, B. MacGillivray, N. Pidgeon, 2017. Homes as machines: exploring expert and public imaginaries of low carbon housing futures in the United Kingdom. Energy Research \& Social Science, 23: 36-45.

[31]. Tidwell, A.S.D., J. Smith, 2015. Morals, materials, and technoscience: the energy security imaginary in the United States. Science, Technology, \& Human Values, 40, 5: 687-711.

[32]. Jameson, F., 2010. Utopia as Method, or the Uses of the Future. In: Gordin, M.D., Tilley, H. and Prakash, G. (Eds.). Utopia/Dystopia: Conditions of Historical Possibility. Princeton: Princeton University Press, $21-44$.

[33]. Sovacool B.K., 2014. Energy studies need social science. Nature 511(7511): 529-530, 31 July. [34]. Sovacool, B.K., S.E. Ryan, P.C. Stern, K. Janda, G. Rochlin, G., Spreng, M.J. Pasqualetti, H. Wilhite, L. Lutzenhiser, 2015. Integrating social science in energy research. Energy Research \& Social Science, 6: 95-99.

[35]. Shove, E., 2014. Putting practice into policy: reconfiguring questions of consumption and climate change. Contemporary Social Science, 9(4): 415-429.

[36]. Ingeborgrud, L., S. Heidenreich, M. Ryghaug, T.M. Skjølsvold, C. Foulds, R. Robison, K. Buchmann, R. Mourik, 2020. Expanding the scope and implications of energy research: a guide to key themes and concepts from the Social Sciences and Humanities. Energy Research \& Social Science, 63: 101398.

[37]. Rochlin, G.I., 2014. Energy research and the contributions of the social sciences: a retrospective examination. Energy Research \& Social Science, 3: 178-185.

[38]. Cooper, A.C.G., 2017. Building physics into the social: enhancing the policy impact of energy studies and energy social science research. Energy Research \& Social Science, 26: 80-86. 
[39]. Castree, N., G. Waitt, 2017. What kind of socio-technical research for what sort of influence on energy policy? Energy Research \& Social Science, 26: 87-90.

[40]. Stern, P., 2017. How can social science research become more influential in energy transitions? Energy Research \& Social Science, 26: 91-95.

[41]. Labanca, N., P. Bertoldi, 2018. Beyond energy efficiency and individual behaviours: policy insights from social practice theories. Energy Policy, 115: 494-502.

[42]. Shove, E., 2017. What is wrong with energy efficiency? Building Research \& Information, 46, 7: 779-789.

[43]. Groves, C., K. Henwood, F. Shirani, C. Butler, K. Parkhill, N. Pidgeon, 2016. The grit in the oyster: using energy biographies to question socio-technical imaginaries of 'smartness'. Journal of Responsible Innovation, 3(1): 4-25.

[44]. Goggins, G., F. Fahy, C.L. Jensen, 2019. Sustainable transitions in residential energy use: Characteristics and governance of urban-based initiatives across Europe. Journal of Cleaner Production, 237: 117776.

[45]. High Level Expert Group, 2015. Commitment and Coherence Ex - Post Evaluation of the 7th EU Framework Programme. Available at:

https://ec.europa.eu/research/evaluations/pdf/fp7 final evaluation expert group report.pdf [46]. European Commission, 2018. Horizon 2020 in Full Swing - Three Years-On - Key Facts and Figures 2014-2016. Available at URL: https://ec.europa.eu/programmes/horizon2020/sites/horizon2020/files/h2020 threeyearson_a4 horizo $\underline{\text { ntal_2018_web.pdf }}$

[47]. European Commission, 2019. Integration of Social Sciences and Humanities in Horizon 2020: Participants, Budgets and Disciplines $-4^{\text {th }}$ Monitoring Report on SSH Flagged Projects Funded in 2017 under the Societal Challenges and Industrial Leadership priorities. Luxembourg: Publications Office of the European Union. 
[48]. Kern, F., K.S. Rogge, M. Howlett, 2019. Policy mixes for sustainability transitions: new approaches and insights through bridging innovation and policy studies. Research Policy, 48(10): 103832. 


\section{Table 1}

\section{Comparing two energy policy imaginaries}

\begin{tabular}{|l|l|l|}
\hline & $\begin{array}{l}\text { Technological and Behavioural } \\
\text { Change }\end{array}$ & $\begin{array}{l}\text { Practices and } \\
\text { Cultural Change }\end{array}$ \\
\hline Framing risks & $\begin{array}{l}\text { Technical challenges; need for } \\
\text { social acceptability }\end{array}$ & $\begin{array}{l}\text { Technological failure; need to } \\
\text { understand energy-related cultures }\end{array}$ \\
\hline Policy focus & $\begin{array}{l}\text { Energy efficiency; uptake of } \\
\text { renewable energy technologies }\end{array}$ & $\begin{array}{l}\text { Changes in energy-related practices; } \\
\text { bottom-up governance }\end{array}$ \\
\hline Controversies & $\begin{array}{l}\text { Ensuring behaviour change; } \\
\text { consumer choice }\end{array}$ & $\begin{array}{l}\text { Understanding change in energy- } \\
\text { related cultures and practices }\end{array}$ \\
\hline Stakes & $\begin{array}{l}\text { Competitiveness; buy-in of } \\
\text { customers }\end{array}$ & $\begin{array}{l}\text { Co-creation of knowledge, shaping } \\
\text { future research agenda }\end{array}$ \\
\hline Closures & $\begin{array}{l}\text { 'Official' policies, formal } \\
\text { regulations and legislative decisions }\end{array}$ & $\begin{array}{l}\text { Informal, local orders, open to } \\
\text { disruption }\end{array}$ \\
\hline $\begin{array}{l}\text { Civic } \\
\text { epistemologies }\end{array}$ & $\begin{array}{l}\text { Enabling consumers to make } \\
\text { 'better' energy choices }\end{array}$ & $\begin{array}{l}\text { Understanding energy-related cultures } \\
\text { and shifting practices }\end{array}$ \\
\hline
\end{tabular}

Source: authors 
Table 2

Relevance of culture to energy use: three dimensions

\begin{tabular}{|l|l|}
\hline Dimension & Description \\
\hline Materiality & $\begin{array}{l}\text { Mundane technology (e.g. central heating } \\
\text { thermostat; tea bags; clothes; slippers) }\end{array}$ \\
\hline Meaning & $\begin{array}{l}\text { Symbols collectively attached to energy use } \\
\text { domains (e.g. keeping the kids warm as good } \\
\text { parenting, communal eating as what 'good' } \\
\text { families do) }\end{array}$ \\
\hline Knowledge & $\begin{array}{l}\text { Skills, know-how implicated with energy use } \\
\text { practices (e.g. setting room thermostats, } \\
\text { dressing warmly, excluding draughts) }\end{array}$ \\
\hline
\end{tabular}

Source: authors 
Table 3

European Research Council funded projects 2007-2018

\begin{tabular}{|l|l|l|}
\hline & $\begin{array}{l}\text { Number of } \\
\text { projects funded } \\
\mathbf{( 2 0 0 7 - 2 0 1 8 )}\end{array}$ & \% Share of Total \\
\hline $\begin{array}{l}\text { Physical Sciences } \\
\text { and Engineering }\end{array}$ & 4082 & 45.2 \\
\hline Life Sciences & 3079 & 34.1 \\
\hline Social Sciences \\
and Humanities & 1864 & 20.7 \\
\hline Total & 9025 & 100.0 \\
\hline
\end{tabular}

Source: ERC website: https://erc.europa.eu/projects-figures/erc-funded-projects 
Table 4

Main national public funders of environmental, sustainability and energy SSH research in eight European countries

\begin{tabular}{|c|c|}
\hline Country & Funding bodies and programmes \\
\hline Denmark & $\begin{array}{l}\text { Innovationsfonden - Innovation Fund Denmark invests in cultivating and } \\
\text { translating ideas, knowledge and technology for the benefit of Danish society. } \\
\text { Danish Energy Agency (resides under the Ministry of Energy, Utilities and } \\
\text { Climate) funds Energiteknologisk udvikling og Demonstrationsprogram (EUDP) - } \\
\text { Energy Technology Development and Demonstration Program. } \\
\text { ELFORSK is the Danish Energy Research and Development Program that } \\
\text { supports research and development in the field of efficient use of energy. } \\
\text { Ministry of Climate, Energy and Building managed ForskEL programme to } \\
\text { support the development and integration of environmentally friendly power } \\
\text { generation technologies for grid connection (shut down in 2017). }\end{array}$ \\
\hline Finland & $\begin{array}{l}\text { Academy of Finland is the main funder which grants competition-based funding } \\
\text { for scientific research, researcher training and development of framework } \\
\text { conditions for research; comprised of four research councils; Culture and Society } \\
\text { RC funds social science research. } \\
\text { Strategic Research Council (SRC) hosted by the Academy of Finland. } \\
\text { Sitra, Finnish Innovation Fund explores and develops operating models for } \\
\text { sustainable well-being based on a One-Planet approach. }\end{array}$ \\
\hline Germany & $\begin{array}{l}\text { Deutsche Forschungsgemeinschaft (DFG, German Research Foundation) is the } \\
\text { central, independent research funding organisation; funds research projects at } \\
\text { universities and other research institutions; funding is provided by the German } \\
\text { federal government and the states. } \\
\text { Federal ministries; Federal Ministry of Education and Research (BMBF) is the } \\
\text { main research funder. }\end{array}$ \\
\hline Hungary & $\begin{array}{l}\text { Hungarian Scientific Research Fund (OTKA) supports internationally excellent } \\
\text { discovery research (i.e. basic research) at Hungarian institutions; primarily } \\
\text { financed by the state. } \\
\text { National Research, Development and Innovation Fund (NKFIA) is managed by } \\
\text { the National Research, Development and Innovation Office (NRDIO) and is open } \\
\text { to the academia, NGOs and enterprises. } \\
\text { Green (NGO) Fund is managed by the Ministry of Rural Development with the } \\
\text { main objective of supporting the implementation of the National Environmental } \\
\text { Programme (NEP). } \\
\text { Cohesion funding (co-financed by EU) - Operational Programmes (OP) of the EU } \\
\text { Structural Funds (2007-2013 and 2014-2020) includes Economic Development } \\
\text { and Innovation OP (GINOP); Competitive Central Hungary OP (VEKOP); } \\
\text { Environment and Energy Efficiency and the Social Renewal OPs). }\end{array}$ \\
\hline
\end{tabular}




\begin{tabular}{|c|c|}
\hline Ireland & $\begin{array}{l}\text { Irish Research Council is the main national funder of basic research across all } \\
\text { disciplines, and the only funder that supports basic SSH research. } \\
\text { Environmental Protection Agency funds largely STEM research; there is scope for } \\
\text { SSH under the sustainability banner (the focus is on resource efficiency and 'hard' } \\
\text { SSH, e.g. socio-economics). } \\
\text { Sustainable Energy Authority of Ireland funds a range of research, development } \\
\text { and demonstration activities relating to the production, supply and use of energy; } \\
\text { primarily fund STEM research, but also focus on "market uptake" and "support } \\
\text { for policy makers". }\end{array}$ \\
\hline Netherlands & $\begin{array}{l}\text { Netherlands Organisation for Scientific Research (NWO) under the responsibility } \\
\text { of the Ministry of Education, Culture and Science funds scientific research at } \\
\text { public research institutions; includes all disciplines and fields of research. } \\
\text { Netherlands Enterprise Agency (RVO) is part of the Ministry of Economic Affairs } \\
\text { and Climate Policy and works at the instigation of ministries and the European } \\
\text { Union. } \\
\text { The Dutch Ministry of Economic Affairs and Climate Policy is the main public } \\
\text { funder of energy and sustainability research. Funding calls and programme } \\
\text { selection is organised via NWO and RVO. }\end{array}$ \\
\hline Switzerland & $\begin{array}{l}\text { Swiss National Science Foundation (SNSF) supports basic science in all academic } \\
\text { disciplines, including National Research Programmes - NRP70 (Energy } \\
\text { Turnaround) and NRP71 (Managing Energy Consumption). } \\
\text { State Secretariat for Education, Research and Innovation (SERI) is the federal } \\
\text { government's agency for national and international matters concerning education, } \\
\text { research and innovation policy. } \\
\text { Commission for Technology and Innovation CTI helps to optimise knowledge and } \\
\text { technology transfer through the use of national thematic networks. } \\
\text { Swiss Network for International Studies (SNIS) supports international research. } \\
\text { Swiss Academy of Humanities and Social Sciences unites } 61 \text { scientific societies } \\
\text { and is a network for the SSH; provides support to priority projects like sustainable } \\
\text { development. } \\
\text { Swiss Federal Office of Energy (SFOE) funds a programme 'Energy - Economy - } \\
\text { Society' to promote application-oriented research in the field of energy policy. } \\
\text { Federal Office for the Environment (FOEN) funds programmes on environmental } \\
\text { issues. }\end{array}$ \\
\hline
\end{tabular}




\begin{tabular}{|c|c|}
\hline UK & $\begin{array}{l}\text { Government departments: } \\
\text { Department for Business, Energy \& Industrial Strategy (BEIS) } \\
\text { Global Challenges Research Fund is an initiative led by BEIS; among challenge } \\
\text { areas - Affordable, reliable, sustainable energy; Sustainable cities and } \\
\text { communities. The GCRF supports UK universities and research organisations in } \\
\text { undertaking challenge-led research where it can add greatest value and has the } \\
\text { greatest potential for impact. } \\
\text { The UK Government's Energy Innovation programme aims to accelerate the } \\
\text { commercialisation of innovative clean energy technologies. } \\
\text { Department for Environment Food \& Rural Affairs (DEFRA) } \\
\text { The National Academies (funded by the Government) - The Royal Society, The } \\
\text { British Academy. } \\
\text { UK Research and Innovation brings together seven Research Councils, Innovate } \\
\text { UK and Research England. } \\
\text { Research Councils UK Energy Programme coordinates the delivery of multi- } \\
\text { disciplinary research in the six priority areas including Energy Programme and } \\
\text { Living with Environmental Change Programme; supports a full spectrum of } \\
\text { energy research and claims significant policy impact. } \\
\text { Economic and Social Research Council (ESRC) funds research in seven national } \\
\text { priority areas including climate change; also funds joint programmes, e.g. NERC- } \\
\text { ESRC's research programme on Unconventional Hydrocarbons in the UK Energy } \\
\text { System: Environmental and socio-economic impacts and processes. }\end{array}$ \\
\hline
\end{tabular}

Source: energise-project.eu/sites/default/files/content/ENERGISE_D6.4_300518_FINAL.pdf 